\title{
The effect of Panton Valentin Leukocidin (PVL) on the airway smooth muscle viability
}

\author{
Rodopi Stamatiou ${ }^{1}$, Efthimia Petinaki ${ }^{2}$, Apostolia Hatziefthimiou ${ }^{1 *}$ \\ ${ }^{1}$ Department of Physiology, Medical School, University of Thessaly, Larissa, Greece \\ ${ }^{2}$ Department of Microbiology, Medical School, University of Thessaly, Larissa, Greece \\ Email: axatzi@med.uth.gr
}

Received 21 November 2012; revised 25 December 2012; accepted 7 January 2013

\begin{abstract}
Methicillin-resistant Staphylococcus aureus (MRSA) is recognized as a worldwide pathogen, and the incidence of community-acquired infections (CA-MRSA) is increased. A virulence factor has been found in most CA-MRSA infections, the Panton-Valentin leukocidin (PVL), which causes polymorphonuclear leukocytes lysis and acute uncontrolled inflammation and tissue injury. In this study we investigated the effect of bacterial supernatant of PVL positive or negative strains on airway smooth muscle obtained from rabbit trachea. MRSA that carry the PVL-gene, confirmed by PCR, is cultured on GP agar and colonies were transferred into casein casein yeast extract medium. The culture supernatants were removed after centrifugation and the presence of PVL was confirmed using an immunochromatographic test. Rabbit tracheal ASMC were isolated and incubated with PVL positive or negative bacterial supernatant (1:20 - 1:2000) for 1 - 3 days. The effect of PVL on the ASMC morphology or viability was estimated using microscope observations or indirect immunofluorescence with anti-Smooth muscle $\alpha$-actin antibody and Dapi for DNA staining, and Trypan blue staining, respectively. ASMC incubated with PVL exhibit increased cell size, granular cytoplasm, and ruptured nuclei. Furthermore, PVL reduces cell number mainly in ASMC incubated in the presence of $10 \%$ FBS, therefore actively proliferating cells. These results show that apart from the known effect of PVL on immune cells and inflammation process, PVL has a direct toxic effect on airway smooth muscle cells.
\end{abstract}

Keywords: Staphylococcus Aureus; PVL; Airway Smooth Muscle Cells

\section{INTRODUCTION}

Over the past decade the incidence of infections caused

"Corresponding author. by methicillin-resistant Staphylococcus aureus (MRSA) stains has been on the rise in both hospitalising patients and healthy subjects living in the community [1]. MRSA stains are associated with skin and soft-tissue infections, as well as severe infections with high mortality, such as sepsis, necrotising fasciitis and necrotising pneumonia [1]. Infections caused by these strains are an emerging public health issue and outbreaks have been described in Australia, Europe and the United States. In Greece, during 2001-2003 a wide-distribution of PVL-MRSA infections was found [2-4].

Epidemiologic and clinical data provide compelling evidence that the high virulence potential of MRSA is associated with the genes lukS-PV and lukF-PV encoding the subunits of the Panton-Valentine leukocidin (PVL) $[5,6]$. Both epidemiologic and clinical data provide compelling evidence that the high virulence potential of MRSA originates from PVL. Epidemiological studies confirm a major role for PVL for the pathogenesis of MRSA infections however animal studies provide contradictory evidence for its pathogenetic role [7]. The main pathogenetic mechanism of PVL is the pores forming in cell membrane and lysis of phagocytes, neutronphils, macrophages and monocytes $[7,8]$.

There are strong epidemiological associations between PVL and highly transmissible, virulent, strains of MRSA for cases of necrotizing pneumonia presenting from the community [9]. The mechanisms of how PVL may cause tissue injury in PVL-positive $S$. aureus necrotizing pneumonia are unknown. The proposed mechanisms are polymorphonuclear leukocytes lysis [8] and acute uncontrolled inflammation and tissue injury [10].

PVL involvement in the pathogenic MRSA disease toxic effect needs further understanding. Since one of the most dangerous PVL/MRSA infections is necrotizing pneumonia, the study of their effect on airway structural cells could be of great importance. In rabbits PVL may cause lung inflammation and necrotizing pneumonia [10]. Based on the hypothesis that apart from the effect of PVL on immune cells and inflammation process, PVL might affect directly airway structural cells, we inves- 
tigated the effect of bacterial supernatant of PVL positive or negative strains on airway smooth muscle obtained from rabbit trachea.

\section{METHODS}

\subsection{Isolation of PVL from a ST80 MRSA Strain}

A ST80 MRSA strain that carry the PVL-gene, confirmed by PCR, was cultured on GP agar (Difco: $10 \mathrm{~g} / 1$ peptone, $5 \mathrm{~g} / \mathrm{l}$ yeast extract, $17 \mathrm{~g} / \mathrm{l}$ agar; Sigma: $5 \mathrm{~g} / \mathrm{l}$ $\mathrm{NaCl}, 1 \mathrm{~g} / \mathrm{l}$ glucose). After $18 \mathrm{~h}$ at $37^{\circ} \mathrm{C}$ some colonies (approximately $107 \mathrm{CFU} / \mathrm{ml}$ ) were transferred into $5 \mathrm{ml}$ of CCY (casein casein yeast extract) broth in a $25 \mathrm{ml}$ glass Erlenmeyer flask. After culturing for $18 \mathrm{~h}$ at $37^{\circ} \mathrm{C}$ with shaking, the culture supernatants were remove after centrifugation $\left(8000 \mathrm{~g}, 4^{\circ} \mathrm{C}\right.$ for $\left.10 \mathrm{~min}\right)$, and then were conserved for a short period at $4^{\circ} \mathrm{C}$ or at $-20^{\circ} \mathrm{C}$ before use. The presence of PVL in the supernatant was confirmed using a commercially available immunochromatographic test (BioMerieux, la Balme les Grottes, France) [11]. The supernatant of ST80 MRSA strain, carrying the PVL-gene, does not contain any other toxins secreted from the bacteria that could affect any cells, apart from PVL.

The same procedure was followed for a strain negative for the PVL-gene. The culture supernatant that was obtained from this strain was used as negative control in our experiments, in order to make sure that any effect that was observed was due to the presence of PVL.

\subsection{ASMCs Isolation and Culture}

The isolation and culture of rabbit tracheal ASMC was done as previously described $[12,13]$. Briefly, tracheal muscle was epithelium denuded, dissected from cartilage and washed in low $\mathrm{Ca}^{2+}$ Krebs solution $(139 \mathrm{mM} \mathrm{NaCl}$, $5.4 \mathrm{mM} \mathrm{KCl}, 1.47 \mathrm{mM} \mathrm{MgSO}$, $11 \mathrm{mM}$ glucose, 1.47 $\mathrm{mM} \mathrm{KH}_{2} \mathrm{PO}_{4}, 2.8 \mathrm{mM} \mathrm{Na}_{2} \mathrm{HPO}_{4}, 1.4 \mathrm{mM} \mathrm{NaHCO} 3,0.2$ $\mathrm{mMCaCl}_{2}$ ). Tracheal smooth muscle was digested in 2 $\mathrm{ml}$ of low $\mathrm{Ca}^{2+} \mathrm{Krebs}$ solution containing $0.25 \%$ bovine serum albumin (BSA), $2 \mathrm{mg} / \mathrm{ml}$ collagenase I and 10 $\mathrm{U} / \mathrm{ml}$ elastase $\mathrm{IV}$, for $30 \mathrm{~min}$ at $37^{\circ} \mathrm{C}$ with vigorous shaking. Then it was washed in low $\mathrm{Ca}^{2+} \mathrm{Krebs}$ solution, centrifuged (1000 rpm for $10 \mathrm{~min}$ ) and incubated in low $\mathrm{Ca}^{2+}$ Krebs solution containing $0.25 \%$ bovine serum albumin (BSA), $1 \mathrm{mg} / \mathrm{ml}$ collagenase I and $20 \mathrm{U} / \mathrm{ml}$ elastase IV. Dispersed ASMCs were washed and centrifuged (1000 rpm for $10 \mathrm{~min}$ ) twice in Dulbecco's modified Eagle's medium/Ham/F12 (DMEM/F12) containing 10\% FBS, $100 \mathrm{U} / \mathrm{ml}$ penicillin and $100 \mu \mathrm{g} / \mathrm{ml}$ streptomycin. The isolated ASMCs were placed in culture flasks and grown at $37^{\circ} \mathrm{C}$ in a humified incubator under $5 \% \mathrm{CO}_{2}$.

\subsection{Cell Culture Treatments}

Cells were trypsinised, counted and seeded into appro- priate cell culture plates. They were allowed to adhere overnight, washed twice with phosphate buffered saline (PBS) and incubated in DMEM/F12 containing $100 \mathrm{U} / \mathrm{ml}$ penicillin and $100 \mu \mathrm{g} / \mathrm{ml}$ streptomycin for 24 hours, in order to become synchronized. ASMCs were then exposed to PVL positive or negative bacterial supernatant (1:20 - 1:2000) for $24-72 \mathrm{~h}$. Cells incubated in DMEM/ F12 represent non proliferating populations; while cells incubated in the presence of $10 \%$ FBS are actively proliferating cells.

All chemicals were purchased from Sigma Aldrich Chemie and all antibodies from Cell Signalling.

\subsection{Observation of PVL Effect on Airway Smooth Muscle Morphology}

\subsubsection{Microscopy}

Treated ASMC were observed under a reverse microscope (Nikon eclipse TS100, Nikon Inc., Melville New York, USA) and photos were taken using a Leica camera (Leica DFC 480, Leica Cameras, Solms, Germany).

\subsubsection{Indirect Immunofluorescence}

ASMC were plated onto glass slides which were resided in culture plates and were fixed with PBS-3\% formaldeyde, rinsed with $\mathrm{PBS}$ and permeabilized with PBS-1\% Triton X-100. Following blocking with PBS$0.1 \%$ Tween $20 \%$ - 3\% BSA, ASMC were incubated with anti-SM a-actin (A104) mouse monoclonal antibody, and with anti-mouse IgG antibody, stained with CY3. Finally, Vectrashield solution, containing DAPI for DNA staining, was added to the cells. ASMC were observed using UV microscopy (Zeiss Axioskop 40, Carl Zeiss Inc., New York, USA) and pictures were taken using a Leica camera (Leica DFC 480, Leica Cameras, Solms, Germany).

\subsection{Measurement of Cultured Airway Smooth Muscle Number}

Trypsinised ASMC were stained with Trypan blue solution and the number of dead as well as total cells was counted using a hemocytometer (Neubauer plaque).

\subsection{Statistical Analysis}

In cell viability experiments each point was performed in triplicate and the values presented are the mean of independent experiments. All data are expressed as means \pm standard error of the mean (SEM) and $\mathrm{N}$ refers to the number of independents experiments. Differences between means were analyzed by one-way ANOVA with Bonferonni's post test or unpaired t-test with statistically significant differences between groups being determined by Mann-Whitney test. A comparison is considered significant when $\mathrm{P}<0.05$. Statistical analysis and graph drawing were performed using GraphPad Prism 4 
(GraphPad software, San Diego, CA, USA).

\section{RESULTS}

The presence of bacterial supernatant of PVL positive strains in the culture medium affects the morphology of ASMC. Specifically, ASMC cultured for $72 \mathrm{~h}$ in the presence of 1:2000 bacterial supernatant of PVL positive strains appear to become enlarged and to lose their monolayer connectivity compared to cells cultured in DMEM-F12 or in DMEM-F12 containing 10\% FBS (Figure 1). On the other hand the presence of bacterial supernatant of PVL negative strains in the culture medium did not affect the cell morphology of ASMC (Figure 1). The observed effect was not dose dependent, since even in the smaller concentrations ASMC incubated with supernatant from PVL positive stains appear damaged. Furthermore, the effect was obvious from the first $24 \mathrm{~h}$ of incubation, but the time point of $72 \mathrm{~h}$ was chosen to be presented, since at that time the effect was more intense.

Indirect immunofluoresence experiments, using anti- $\alpha$-actin antibody show that, no major change of the actin cytoskeleton is apparent in cells cultured for $24 \mathrm{~h}$ in the presence of 1:2000 bacterial supernatant of PVL positive strains and DMEM-F12 alone (Figure 2(a)). In contrast, $\alpha$-actin filaments appear destroyed and $\alpha$-actin to be concentrated in distinct granular foci in cells cultured in the presence of 1:2000 bacterial supernatant of PVL positive strains and DMEM-F12 with 10\% FBS (Figure 2(b)). Under these conditions some nuclei seem damaged and their DNA erupted as shown by DAPI staining (Figure 2(b)).

The presence of bacterial supernatant of PVL positive strains in the culture medium for $72 \mathrm{~h}$ did not affect cell number incubated without 10\% FBS (Figure 3), while it reduced, in a dose-independent way, the ability of ASMC to proliferate in the presence of 10\% FBS (Figure 3). Namely, in the presence of 1:2000 bacterial supernatant of PVL positive strains cell number decreased from $176,563 \pm 5337$ to $115,625 \pm 12,103(\mathrm{~N}=4, \mathrm{p}<$ 0.01). On the other hand ASMC incubation for 3 days in bacterial supernatant of PVL negative strains did not affect neither cell number cultured in the presence or absence of 10\% FBS (Figure 4).

\section{DISCUSSION}

The most frequent manifestations of methicillin-resistant S. aureus (MRSA) are skin and soft tissue infections but
DMEM-F 12

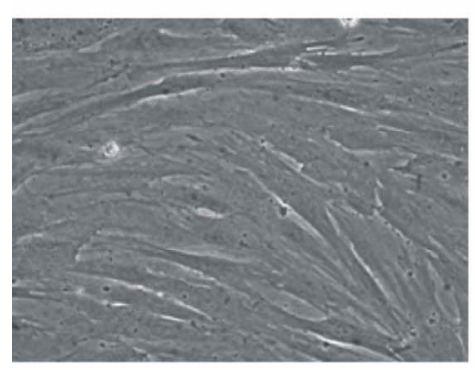

DMEM-F $12+10 \%$ FBS

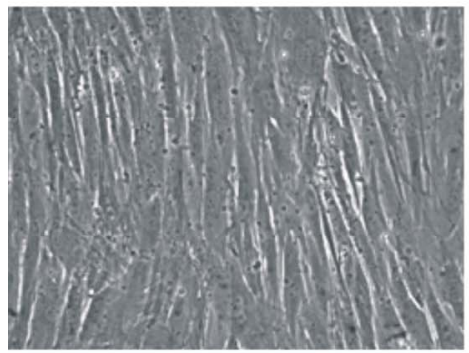

DMEM-F12

$+$

bacterial supernatant of PVL (-) strains

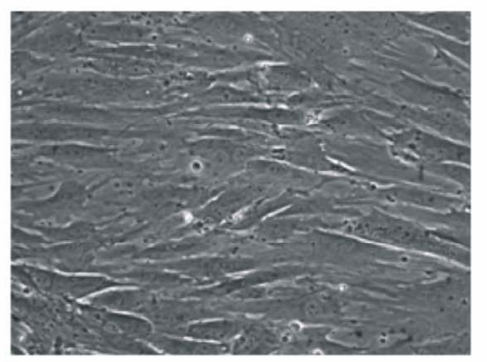

(a)

DMEM-F $12+10 \%$ FBS

bacterial supernatant of PVL (-) strains

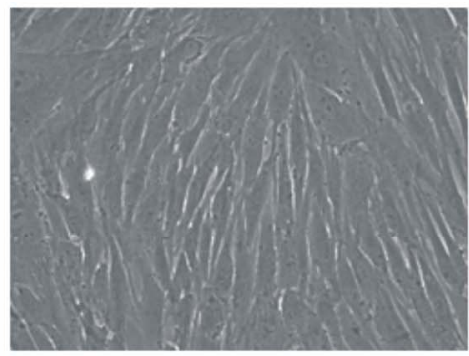

(b)
DMEM-F12

$+$

bacterial supernatant of PVL $(+)$ strains

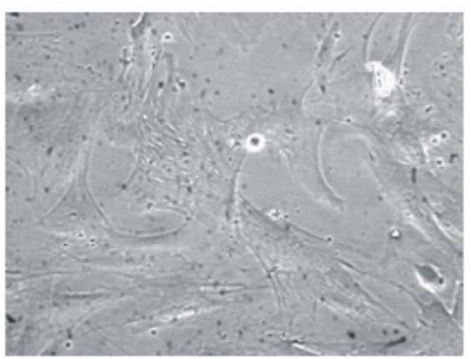

DMEM-F $12+10 \%$ FBS

bacterial supernatant of PVL $(+)$ strains

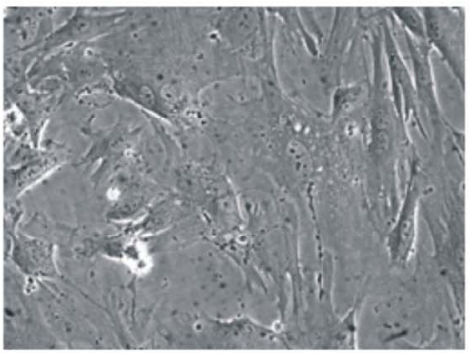

Figure 1. The effect of bacterial supernatant of PVL positive and PVL negative strains on ASMC morphology. ASMCs were cultured for $72 \mathrm{~h}$ in DMEM-F12 or DMEM-F12 and 10\% FBS in the presence or absence of 1:2000 bacterial supernatant. Microscopy magnification was set on 20 . 


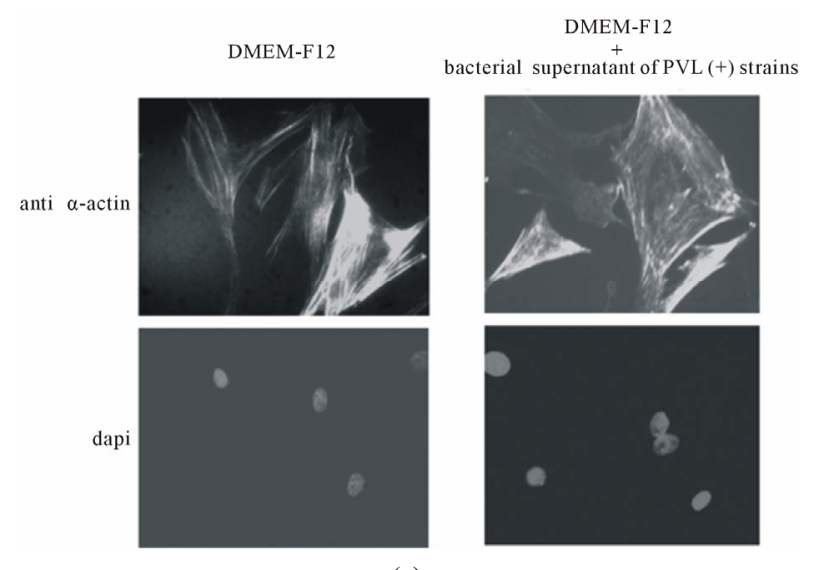

(a)

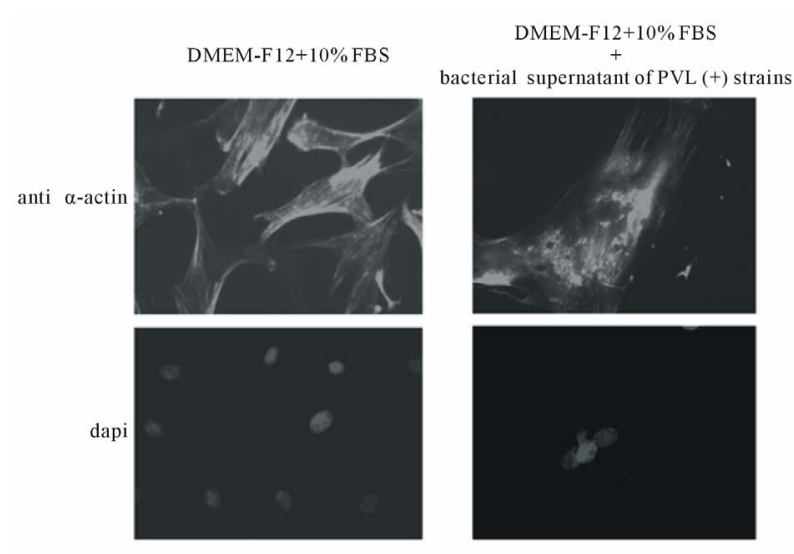

(b)

Figure 2. Indirect immunofluoresence, using anti- $\alpha$-actin antibody and dapi staining of ASMC cultured for $24 \mathrm{~h}$ in DMEMF12 or DMEM-F12 and 10\% FBS in the presence or absence of 1:2000 bacterial supernatant. Microscopy magnification was set on 20 .

these strains also cause highly invasive, rapidly progressing fatal diseases such as necrotizing pneumonia and necrotizing fasciitis $[14,15]$. The genetic markers distinguish methicillin-resistant $S$. aureus strains from others are their genetic lineage, the composition of their methicillin resistance element, and the presence of the genes encoding Panton-Valentine leukocidin (PVL) [14, 16]. Evidence suggests the contribution of PVL to methicillin-resistant $S$. aureus disease mainly by the toxic effect of PVL on cells of immune system $[17,18]$. In this study, we demonstrate that bacterial supernatant of PVL positive strains have a direct toxic effect on airway smooth muscle cells.

We first studied the effect of bacterial supernatant of PVL positive strains on the ASMC morphology using microscope observations, indirect immunofluorescence using anti-Sm $\alpha$-actin antibody and DAPI for DNA staining. The morphologic appearance of ASMCs incubated in the presence of bacterial supernatant of PVL positive strains like enlarged ASMCs (Figure 1), des-

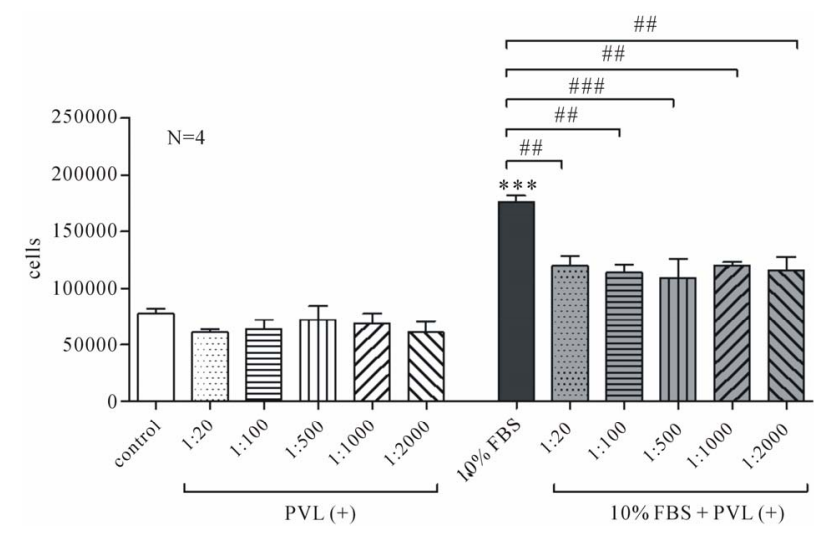

Figure 3. The effect of bacterial supernatant of PVL positive strains on ASMC viability. ASMCs were incubated for $72 \mathrm{~h}$ in DMEM-F12 or DMEM-F12 and 10\% FBS in the presence or absence of 1:20 to 1:2000 bacterial supernatant and cell number was estimated with Trypan Blue method. Data are presented as mean \pm SEM from 4 independent experiments. ${ }^{* * *} \mathrm{P}<0.001$ compared to control (unpaired t-test, Mann-Whitney test) and ${ }^{\# \#} \mathrm{P}<0.01$ and ${ }^{\# \# \#} \mathrm{P}<0.001$ (One-way ANOVA with statisticcally significant differences between groups being determined by Bonferonni's post test).

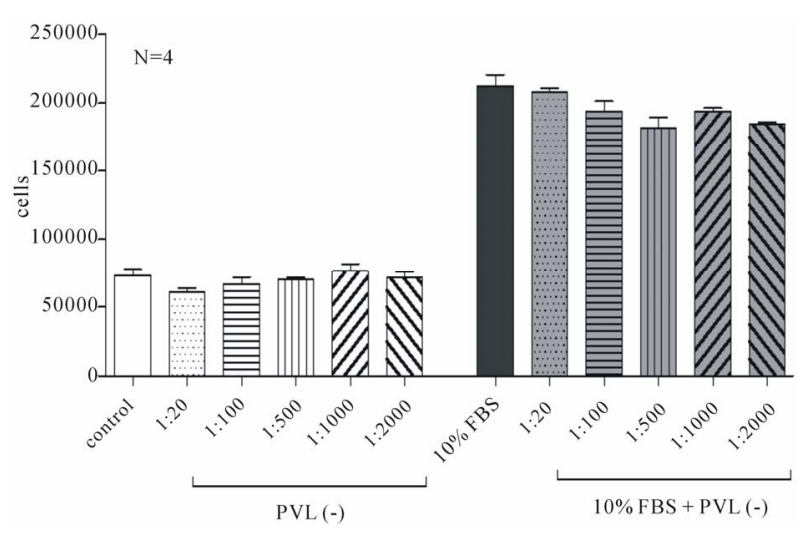

Figure 4. The effect of bacterial supernatant of PVL negative strains on ASMC viability. ASMCs were incubated for $72 \mathrm{~h}$ in DMEM-F12 or DMEM-F12 and 10\% FBS in the presence or absence of 1:20 to 1:2000 bacterial supernatant and cell number was estimated with Trypan Blue method.

troyed $\alpha$-actin filaments and damaged nuclei seem with erupted DNA (Figure 2), suggest the initiation of cell death. In order to verify the effect of bacterial supernatant of PVL positive strains on the ASMC viability, Trypan blue staining was used and we found that ASMCs incubation with such supernatant reduces cell number mainly in ASMC incubated in the presence of 10\% FBS (Figure 3). On the other hand, the presence of bacterial supernatant of PVL negative strains in the culture medium did not affect the ASMC morphology (Figure 1) or cell viability (Figure 4) suggesting that the above effect are specific for PVL positive strains as when ASMCs were incubated with supernatant of PVL negative strains no major changes on cell morphology 
and viability were observed.

In addition, the effect of bacterial supernatant of PVL positive strains on cell morphology and viability seems to depend on ASMC phenotype. Namely, cells incubated in DMEM-F12 alone, that express a contractile phenoltype were not affected by bacterial supernatant compared to "proliferative" ASMCs cultured in DMEM-F12 containing $10 \%$ FBS $[19,20]$. This differentiation in the PVL positive supernatant effect may be caused by the fact that proliferating cells are more sensitive to stimuli.

Methicillin-resistant $S$. aureus stains are also associated with production of other toxins, such as staphylococcal enterotoxin $\mathrm{Q}$ and $\mathrm{K}, \alpha$-hemolysin both epidemic ologic and clinical data provide compelling evidence that the high virulence potential of MRSA originates from PVL $[21,22]$. In our experiments we used bacterial supernatant from ST80 MRSA strain that carry the PVLgene. This stain is well characterized and the supernatant of ST80 MRSA strain, carrying the PVL-gene, does not contain any other toxins secreted from the bacteria that could affect any cells, apart from PVL [23]. Therefore, we can suggest that the effect of bacterial supernatant of PVL positive strains on ASMC morphology and viability due to PVL effect.

In vitro studies demonstrated a concentration-dependent PVL effect leading to either apoptosis or necrosis in neutrophils exposed to different toxin concentrations. The toxic effect of PVL involves pore formation in the mitochondria membrane. Studies in human neutrophils demonstrated that PVL effect is time-dependent as sublytic concentrations of PVL trigger apoptosis within 6 hours of treatment, whereas higher toxin concentrations cause cell lysis within 1 hour [11]. In our experiments a dose-dependent effect was not demonstrated possibly due to the long period of cell incubation with bacterial supernatant of PVL positive strains ( $24-72 \mathrm{~h}$ ).

Epidemiological data and animal infection models demonstrate that PVL contributes to the severity of necrotizing pneumonia $[10,17]$. Therefore our findings suggesting the possible direct toxic effect of PVL on ASMCs may point out a pathogenetic mechanism of methicillin-resistant Staphylococcus aureus infections in parallel with their toxic effect on immune cells.

\section{CONCLUSION}

In conclusion, bacterial supernatant of PVL positive strains has a toxic effect on the ASMC morphology and viability possibly due to PVL, which might be of clinical significance.

\section{REFERENCES}

[1] Pantosti, A. and Venditti, M. (2009) What is MRSA?
European Respiratory Journal, 34, 1190-1196. doi:10.1183/09031936.00007709

[2] Dailiana, Z.H., Rigopoulos, N., Varitimidis, S.E., Poultsides, L., Petinaki, E. and Malizos, K.N. (2008) Clinical and epidemiological features of upper-extremity infections caused by Staphylococcus aureus carrying the PVL gene: A four-year study in Greece. Medical Science Monitor, 14, CR511-CR514.

[3] Chini, V., Petinaki, E., Foka, A., Paratiras, S., Dimitracopoulos, G. and Spiliopoulou, I. (2006) Spread of Staphylococcus aureus clinical isolates carrying PantonValentine leukocidin genes during a 3-year period in Greece. Clinical Microbiology and Infection, 12, 29-34. doi:10.1111/j.1469-0691.2005.01295.x

[4] Chini, V., Petinaki, E., Meugnier, H., Foka, A., Bes, M., Etienne, J., Dimitracopoulos, G. and Spiliopoulou, I. (2008) Emergence of a new clone carrying Panton-Valentine leukocidin genes and staphylococcal cassette chromosome mec type $\mathrm{V}$ among methicillin-resistant Staphylococcus aureus in Greece. Scandinavian Journal of Infectious Diseases, 40, 368-372. doi: $10.1080 / 00365540701749230$

[5] Vandenesch, F., Naimi, T., Enright, M.C., Lina, G., Nimmo, G.R., Heffernan, H., Liassine, N., Bes, M., Greenland, T., Reverdy, M.E. and Etienne, J. (2003) Community-acquired methicillin-resistant Staphylococcus aureus carrying Panton-Valentine leukocidin genes: Worldwide emergence. Emerging Infectious Diseases, 9, 978-984. doi:10.3201/eid0908.030089

[6] Adem, P.V., Montgomery, C.P., Husain, A.N., Koogler, T.K., Arangelovich, V., Humilier, M., Boyle-Vavra, S. and Daum, R.S. (2005) Staphylococcus aureus sepsis and the Waterhouse-Friderichsen syndrome in children. New England Journal of Medicine, 353, 1245-1251. doi:10.1056/NEJMoa044194

[7] Nastaly, P., Grinholc, M. and Bielawski, K.P. (2010) Molecular characteristics of community-associated methicillin-resistant Staphylococcus aureus strains for clinical medicine. Archives of Microbiology, 192, 603-617. doi:10.1007/s00203-010-0594-4

[8] Boyle-Vavra, S. and Daum, R.S. (2007) Communityacquired methicillin-resistant Staphylococcus aureus: The role of Panton-Valentine leukocidin. Laboratory Investigation, 87, 3-9. doi:10.1038/labinvest.3700501

[9] Shilo, N. and Quach, C. (2011) Pulmonary infections and community associated methicillin resistant Staphylococcus aureus: A dangerous mix? Paediatric Respiratory Reviews, 12, 182-189. doi:10.1016/j.prrv.2010.10.007

[10] Diep, B.A., Chan, L., Tattevin, P., Kajikawa, O., Martin, T.R., Basuino, L., Mai, T.T., Marbach, H., Braughton, K.R., Whitney, A.R., Gardner, D.J., Fan, X., Tseng, C.W., Liu, G.Y., Badiou, C., Etienne, J., Lina, G., Matthay, M.A., DeLeo, F.R. and Chambers, H.F. (2010) Polymorphonuclear leukocytes mediate Staphylococcus aureus Panton-Valentine leukocidin-induced lung inflammation and injury. Proceedings of the National Academy of Sciences of the USA, 107, 5587-5592. doi:10.1073/pnas.0912403107

[11] Badiou, C., Dumitrescu, O., George, N., Forbes, A.R., 
Drougka, E., Chan, K.S., Ramdani-Bouguessa, N., Meugnier, H., Bes, M., Vandenesch, F., Etienne, J., Hsu, L.Y., Tazir, M., Spiliopoulou, I., Nimmo, G.R., Hulten, K.G. and Lina, G. (2010) Rapid detection of Staphylococcus aureus Panton-Valentine leukocidin in clinical specimens by enzyme-linked immunosorbent assay and immunochromatographic tests. Journal of Clinical Microbiology, 48, 1384-1390. doi:10.1128/JCM.02274-09

[12] Chachami, G., Hatziefthimiou, A., Liakos, P., Ioannou, M.G., Koukoulis, G.K., Bonanou, S., Molyvdas, P.A., Simos, G. and Paraskeva, E. (2007) Exposure of differentiated airway smooth muscle cells to serum stimulates both induction of hypoxia-inducible factor- $1 \alpha$ and airway responsiveness to ACh. American Journal of PhysiologyLung Cellular and Molecular Physiology, 293, L913-922. doi:10.1152/ajplung.00459.2006

[13] Stamatiou, R., Paraskeva, E., Boukas, K., Gourgoulianis, K.I., Molyvdas, P.A. and Hatziefthimiou, A.A. (2009) Azithromycin has an antiproliferative and autophagic effect on airway smooth muscle cells. European Respiratory Journal, 34, 721-730. doi:10.1183/09031936.00089407

[14] Lo, W.T. and Wang, C.C. (2011) Panton-Valentine leukocidin in the pathogenesis of community-associated methicillin-resistant Staphylococcus aureus infection. Pediatrics \& Neonatology, 52, 59-65. doi:10.1016/j.pedneo.2011.02.008

[15] Kahl, B.C. (2010) Impact of Staphylococcus aureus on the pathogenesis of chronic cystic fibrosis lung disease. International Journal of Medical Microbiology, 300, 514519. doi:10.1016/j.ijmm.2010.08.002

[16] Gerogianni, I., Mpatavanis, G., Gourgoulianis, K., Maniatis, A., Spiliopoulou, I. and Petinaki, E. (2006) Combination of staphylococcal chromosome cassette SCCmec type V and Panton-Valentine leukocidin genes in a methicillin-resistant Staphylococcus aureus that caused necrotizing pneumonia in Greece. Diagnostic Microbiology and Infectious Disease, 56, 213-216. doi:10.1016/j.diagmicrobio.2006.06.005
[17] Löffler, B., Hussain, M., Grundmeier, M., Brück, M., Holzinger, D., Varga, G., Roth, J., Kahl, B.C., Proctor, R.A. and Peters, G. (2010) Staphylococcus aureus panton-valentine leukocidin is a very potent cytotoxic factor for human neutrophils. PLOS Pathogens, 6, e1000715. doi:10.1371/journal.ppat.1000715

[18] Genestier, A.L., Michallet, M.C., Prévost, G., Bellot, G., Chalabreysse, L., Peyrol, S., Thivolet, F., Etienne, J., Lina, G., Vallette, F.M., Vandenesch, F. and Genestier, L. (2005) Staphylococcus aureus Panton-Valentine leukocidin directly targets mitochondria and induces Bax-independent apoptosis of human neutrophils. Journal of Clinical Investigation, 115, 3117-3127. doi:10.1172/JCI22684

[19] Moskowitz, S.M. and Wiener-Kronish, J.P. (2010) Mechanisms of bacterial virulence in pulmonary infections. Current Opinion in Critical Care, 16, 8-12. doi:10.1097/MCC.0b013e3283354710

[20] Amrani, Y. and Panettieri, R.A. (2003) Airway smooth muscle: Contraction and beyond. International Journal of Biochemistry \& Cell Biology, 35, 272-276. doi:10.1016/S1357-2725(02)00259-5

[21] Vignola, A.M., Mirabella, F., Costanzo, G., Di Giorgi, R., Gjomarkaj, M., Bellia, V. and Bonsignore, G. (2003) Airway remodeling in asthma. Chest, 123, 417S-422S. doi:10.1378/chest.123.3 suppl.417S-a

[22] Lazaar, A.L. and Panettieri Jr., R.A. (2001) Airway smooth muscle as an immunomodulatory cell: A new target for pharmacotherapy? Current Opinion in Pharmacology, 1, 259-264. doi:10.1016/S1471-4892(01)00046-7

[23] Wannet, W.J., Spalburg, E., Heck, M.E., Pluister, G.N., Tiemersma, E., Willems, R.J., Huijsdens, X.W., de Neeling, A.J. and Etienne, J. (2005) Emergence of virulent methicillin-resistant Staphylococcus aureus strains carrying Panton-Valentine leucocidin genes in The Netherlands. Journal of Clinical Microbiology, 43, 3341-3345. doi:10.1128/JCM.43.7.3341-3345.2005 